\title{
MICRONUTRIENTES E ÓXIDOS DE FERRO EM COPRÓLITOS DE MINHOCAS PRODUZIDOS EM UM LATOSSOLO VERMELHO DISTROFÉRRICO (OXISOL) SOB DIFERENTES SISTEMAS DE MANEJO
}

\author{
Marie Luise Carolina BARTz, ${ }^{1}$ Antonio Carlos Saraiva da Cost,${ }^{2}$ Ivan \\ Granemann de SouzA Jr. ${ }^{2} \&$ George G. BROWN ${ }^{3}$ \\ ${ }^{1}$ Universidade Estadual de Londrina. Endereço: Rodovia Celso Garcia Cid, PR $445 \mathrm{Km}$ 480, Caixa \\ Postal 6001,CEP 86051-990, Londrina, Paraná, Brasil. E-mail: bartzmarie@gmail.com. \\ ${ }^{2}$ Universidade Estadual de Maringá, Endereço: Av. Colombo 5760, CEP 87020-190, Maringá, Paraná, \\ Brasil. E-mail: antoniocscosta@gmail.com, igsjunior@gmail.com. \\ ${ }^{3}$ Empresa Brasileira de Pesquisa Agropecuária - Florestas. Endereço: Estrada da Ribeira, km 111, CEP \\ 83411-000, Curitiba, Paraná, Brasil. E-mail: browng@cnpf.embrapa.br
}

Bartz, M. L. C., A. C. S. da Costa, I. G. de Souza Jr. \& G. G. Brown. 2010. Micronutrientes e óxidos de ferro em coprólitos de minhocas produzidos em um Latossolo Vermelho distroférrico (Oxisol) sob diferentes sistemas de manejo. Acta Zoológica Mexicana (n.s.), Número Especial 2: 281-294.

RESUMO. As estruturas biogênicas produzidas pelas minhocas modificam os atributos químicos e mineralógicos do solo. Estas alterações são pouco conhecidas em solos altamente intemperizados neotropicais invadidos por minhocas peregrinas e exóticas. Este trabalho teve como objetivo avaliar as alterações na disponibilidade de micronutrientes e nos óxidos de ferro de um Latossolo Vermelho distroférrico (LVdf) (Oxisol) sob diferentes condições de manejo quando invadidos pelas minhocas Pontoscolex corethrurus e Amynthas gracilis. Os micronutrientes analisados foram zinco $(\mathrm{Zn})$, cobre $(\mathrm{Cu})$, manganês $(\mathrm{Mn})$ e ferro $(\mathrm{Fe})$. Os óxidos de ferro foram analisados através de métodos de dissolução seletiva quantificando-se as alterações nos teores de ferro livre $\left(\mathrm{Fe}_{\mathrm{d}}\right)$ e amorfo $\left(\mathrm{Fe}_{\mathrm{o}}\right)$ e alumínio e manganês presentes nos óxidos de ferro por substituição isomórfica livres $\left(\mathrm{Al}_{\mathrm{d}}\right.$ e $\left.\mathrm{Mn}_{\mathrm{d}}\right)$ e amorfos $\left(\mathrm{Al}_{\mathrm{o}}\right.$ e $\left.\mathrm{Mn}_{\mathrm{o}}\right)$. Solo foi coletado sob mata nativa, dois agroecossistemas de plantio direto e uma pastagem, seco ao ar, peneirado e umedecido para a incubação das minhocas e posterior obtenção de coprólitos. A análise dos atributos químicos e mineralógicos dos coprólitos mostrou que, de modo geral, foram observados aumentos nos teores de $\mathrm{Fe}_{\mathrm{d}}$ e $\mathrm{Fe}_{\mathrm{o}}$ nos coprólitos comparados ao solo controle. O oposto foi observado para os teores de $\mathrm{Al}_{\mathrm{d}}$ e $\mathrm{Al}_{\mathrm{o}}$, havendo diminuição dos teores nos coprólitos. Para os teores de $\mathrm{Mn}_{\mathrm{d}}$ e $\mathrm{Mn}_{\mathrm{o}}$ não houve diferenças significativas. Os coprólitos concentraram maiores teores de $\mathrm{Zn}, \mathrm{Cu}$ e $\mathrm{Mn}$, mas tiveram teores mais baixos de Fe disponível. A atividade das minhocas influiu, em geral, de forma positiva sobre os teores de micronutrientes e de óxidos de ferro livre e amorfo no LVdf sob diferentes sistemas de manejo estudado.

Palavras chave: Pontoscolex corethrurus, Amynthas gracilis, fertilidade do solo, agroecossistemas.

Recibido: 16/05/2008; aceptado: 08/01/2010. 
Bartz, M. L. C., A. C. S. da Costa, I. G. de Souza Jr. \& G. G. Brown. 2010. Micronutrientes y óxidos de fierro en heces de lombrices de tierra producidas en un Latosol Rojo distroférrico (Oxisol) bajo diferentes sistemas de manejo. Acta Zoológica Mexicana (n.s.), Número Especial 2: 281-294.

RESUMEN. Las estructuras biogénicas producidas por las lombrices modifican los atributos químicos y mineralógicos del suelo. Estas alteraciones son poco conocidas en suelos altamente intemperados neotropicales invadidos por lombrices peregrinas e exóticas. Este trabajo tuvo como objeto evaluar las alteraciones en la disponibilidad de micronutrientes y en los óxidos de hierro de un Latosol Rojo distroférrico (LVdf) (Oxisol) bajo diferentes condiciones de manejo, al ser invadido por las lombrices Pontoscolex corethrurus y Amynthas gracilis. Los micronutrientes analizados fueron zinc $(\mathrm{Zn})$, cobre $(\mathrm{Cu})$, manganeso $(\mathrm{Mn})$ e hierro (Fe). Los óxidos de hierro fueron analizados a través de métodos de disolución selectiva, siendo cuantificadas las alteraciones en los contenidos de hierro libre $\left(\mathrm{Fe}_{\mathrm{d}}\right)$ y amorfo $\left(\mathrm{Fe}_{\mathrm{o}}\right)$ y aluminio y manganeso presentes en los óxidos de hierro por sustitución isomórfica libres $\left(\mathrm{Al}_{\mathrm{d}} \mathrm{y} \mathrm{Mn}_{\mathrm{d}}\right)$ y amorfos $\left(\mathrm{Al}_{\mathrm{o}} \mathrm{y} \mathrm{Mn}_{\mathrm{o}}\right)$. Suelo fue recolectado bajo bosque nativo, dos agroecosistemas de plantación directa y un pastizal, secado al aire, tamizado y humectado para la incubación de las lombrices y posterior obtención de deyecciones. El análisis de los atributos químicos y mineralógicos de las deyecciones mostró que, por lo general, se observó un incremento del contenido de $\mathrm{Fe}_{\mathrm{d}} \mathrm{y} \mathrm{Fe}_{\mathrm{o}}$ en las deyecciones comparado al suelo de control. Lo opuesto fue observado para los contenidos de $\mathrm{Al}_{\mathrm{d}} \mathrm{y} \mathrm{Al}$, con reducción de los contenidos en las deyecciones. No hubo diferencias significativas en los contenidos de $\mathrm{Mn}_{\mathrm{d}}$ y $\mathrm{Mn}_{\mathrm{o}}$. Las deyecciones concentraron mayores contenidos de $\mathrm{Zn}, \mathrm{Cu}$ y $\mathrm{Mn}$, pero tuvieron contenidos menores de Fe disponible. La actividad de las lombrices influyó, por lo general, en forma positiva sobre los contenidos de micronutrientes y de óxidos de hierro libre y amorfo en el LVdf bajo los diferentes sistemas de manejo estudiados.

Palabras clave: Pontoscolex corethrurus, Amynthas gracilis, fertilidad del suelo, agroecosistemas

\section{INTRODUÇÃO}

O intemperismo dos minerais e das rochas em ambientes naturais tem sido atribuído geralmente aos processos abióticos. No entanto, estudos recentes têm mostrado que os processos bióticos também participam do intemperismo químico, promovendo alterações e dissoluções de minerais silicatados e rochas, induzidas por plantas superiores (Hinsinger et al. 2001), por liquens (Chen et al. 2000), por fungos e por bactérias (Santelli et al. 2001, Song 2006). Estes organismos contribuem muito para a formação do solo através da decomposição direta dos minerais silicatados, aumentando a disponibilidade dos elementos químicos contidos neles.

A atividade da macrofauna do solo, especialmente das minhocas e dos cupins, também desempenha um papel importante na pedogênese e na melhoria da fertilidade do solo (Lee 1983). Os hábitos alimentares das diferentes espécies de cupins e de minhocas afetam a fragmentação e incorporação da matéria orgânica dentro do solo e a estrutura do solo, com a formação de agregados, poros e canais para aeração (Lee 1983, 1985). A passagem pelo intestino da minhoca permite uma íntima mistura dos minerais de argila e materiais orgânicos, os quais são incrustados por muco para produzir os novos microagregados (Shipitalo \& Protz 1989; Barois et al. 1993).

Efeitos químicos da ingestão do solo pelas minhocas têm sido mencionados por diversos autores (Joshi \& Kelkar 1952, Lee 1985, Basker et al. 1993, 1994. Barois 
et al. 1999, Hernández-Castellanos et al., este número). Porém, são poucos e raros os estudos sobre a disponibilidade de micronutrientes nos coprólitos. A maior parte das informações disponíveis (em macronutrientes) está concentrada na análise de coprólitos coletados a campo e comparados com o solo adjacente (Lal \& De Vleeschauver 1982, Hullegale \& Ezumah 1991, Quadros et al. 2002). No entanto, poucos experimentos têm sido conduzidos sob condições controladas para confirmar estes resultados (Basker et al. 1992).

Existe também pouca publicação específica a respeito de alterações mineralógicas provocada pelas minhocas. Animais do solo geófagos, incluindo as minhocas, ingerem grandes quantidades de grãos minerais junto com partículas orgânicas e os excretam na forma de agregados do solo. Estudos indicam que o tamanho médio dos grãos minerais nos coprólitos é geralmente menor do que o do solo adjacente, sugerindo que as minhocas quebram mecanicamente os grãos minerais durante a ingestão e digestão das frações do solo (Evans 1948, Joshi \& Kelkar 1952, Basker et al. 1994), enquanto outros atribuem este fenômeno à ingestão seletiva de finos grãos pelas minhocas (De Vleeschauwer \& Lal 1981, Lal \& Akinremi 1983, Hullegalle \& Ezumah 1991, Nooren et al. 1995, Barois et al. 1999). Em apoio à primeira opção, Suzuki et al. (2003), encontraram grãos minerais arredondados nos coprólitos de Eisenia fetida, os quais não estavam presentes nas amostras de minerais preparadas antes da ingestão, evidenciando o efeito da quebra de grãos minerais pelas minhocas.

Needham et al. (2004), mostraram como anelídeos terrestres e aquáticos eram capazes de degradar diversos minerais e criar um ambiente propício para a diagênese de minerais da argila. Ambas as espécies utilizadas no experimento (Arenicola marina e Lumbricus terrestris) aceleraram, portanto, o processo de intemperismo. Estes efeitos já haviam sido observados em microorganismos (Barker et al. 1998), mas ainda não haviam sido demonstrados adequadamente para a macrofauna.

Os principais materiais responsáveis pela geração de cargas variáveis nos solos tropicais são a matéria orgânica, a caulinita e os óxidos e hidróxidos de Fe e Al (Dias et al. 2003). Existe, desta forma, uma estreita relação entre os teores de carbono orgânico, os teores de óxidos de ferro e alumínio, a disponibilidade de micronutrientes e o pH do solo. Por exemplo, em condições ácidas, o hidrogênio é fortemente retido ao grupo hidroxila e a carboxila da superfície da matéria orgânica, e não é de fácil substituição por outros cátions. A elevação do $\mathrm{pH}$ ioniza hidrogênios que são trocados por cátions, entre eles, os micronutrientes (Camargo 1991). A matéria orgânica, que possibilita um ambiente mais redutor, favorece também a formação de óxidos de Fe e Al pouco cristalinos (Kämpf 1988, Kämpf \& Curi 2000).

Como a atividade das minhocas possui efeitos conhecidos sobre o $\mathrm{pH}$ do solo e a decomposição da matéria orgânica, através da produção de coprólitos, construção de túneis e galerias, espera-se também que influencie os teores e, conseqüentemente, a disponibilidade dos micronutrientes e dos minerais óxidos de $\mathrm{Fe}$ e Al nas formas 
pouco cristalinas e livres. Porém, existem poucos dados sobre o efeito de minhocas comuns na região tropical sobre a disponibilidade de minerais óxidos e micronutrientes no solo. Em um estudo realizado por Oyedele et al. (2006), por exemplo, se observou que os coprólitos da minhoca Hyperiodrilus africanus tinham teores significativamente maiores de óxidos de ferro e alumínio nas formas cristalinas e pouco cristalinas ou amorfas do que no horizonte A do solo utilizado.

Este estudo teve como objetivo, portanto, determinar as variações nos teores dos micronutrientes zinco $(\mathrm{Zn})$, cobre $(\mathrm{Cu})$, manganês $(\mathrm{Mn})$ e ferro $(\mathrm{Fe})$ e nos teores de óxidos de ferro livre $\left(\mathrm{Fe}_{\mathrm{d}}\right)$ e amorfo $\left(\mathrm{Fe}_{\mathrm{o}}\right)$ e alumínio e manganês presentes nos óxidos de ferro por substituição isomórfica livres $\left(\mathrm{Al}_{\mathrm{d}}\right.$ e $\left.\mathrm{Mn}_{\mathrm{d}}\right)$ e amorfos $\left(\mathrm{Al}_{\mathrm{o}}\right.$ e $\left.\mathrm{Mn}_{\mathrm{o}}\right)$ em coprólitos comparados ao solo original e ao solo adjacente, produzidos por duas espécies de minhocas, em um Latossolo Vermelho distroférrico, sob diferentes sistemas de manejo.

\section{MATERIAL E MÉTODOS}

Solo classificado como Latossolo Vermelho distroférrico (LVdf) sob mata (MT), plantio direto (PD), plantio direto subsolado (PDS) e pastagem (PT) foi coletado e peneirado. Em caixas plásticas foram inoculadas duas minhocas adultas das espécies Pontoscolex corethrurus (Müller 1857) (Pc) e Amynthas gracilis (Kinberg 1867) $(\mathrm{Ag})$ com solo umedecido de cada sistema de manejo. Periodicamente (a cada 7, 10 ou 14 dias) foram coletados os coprólitos, que foram secos em estufa e estocados para as análises.

Maiores detalhes sobre as características das áreas, dados sobre a metodologia de coleta do solo, cultivo das minhocas, análise dos coprólitos e do solo trabalhado pelas minhocas, e sobre o delineamento experimental, a análise de $\mathrm{pH} \mathrm{CaCl}_{2}$, carbono orgânico total (COT) e alumínio (Al) estão descritos em Bartz et al. (este número).

Os teores dos micronutrientes zinco $(\mathrm{Zn})$, manganês $(\mathrm{Mn})$, cobre $(\mathrm{Cu})$ e ferro $(\mathrm{Fe})$ foram determinados, após extração com solução Mehlich1, por espectrofotometria de absorção atômica, segundo metodologia descrita em Embrapa (1999). As formas de ferro (Fe) com baixo grau de cristalinidade (amorfos) e alumínio ( $\mathrm{Al}$ ) e manganês (Mn) presentes nos óxidos de ferro por substituição isomórfica foram determinadas por dissolução seletiva do material, na ausência de luz, com oxalato ácido de amônio, conforme metodologia descrita em Camargo et al. (1986). Foram determinados os teores de $\mathrm{Fe}, \mathrm{Al}$ e $\mathrm{Mn}$ presentes no extrato por espectrofotometria de absorção atômica. Para o $\mathrm{Fe}^{3+}$ e o $\mathrm{Mn}^{2+}$ foi utilizada chama de ar-acetileno e para o $\mathrm{Al}^{3+}$ chama de óxido nitroso-acetileno. Os valores obtidos foram expressos na forma de g $100 \mathrm{~g}^{-1} \mathrm{de} \mathrm{Fe}_{\mathrm{o}}$, $\mathrm{Al}_{\mathrm{o}}$ e $\mathrm{Mn}_{\mathrm{o}}$ presentes nas formas pouco cristalinas (amorfos).

Os teores de Fe livres e os de $\mathrm{Al}$ e Mn constituintes destes óxidos foram determinados após dissolução seletiva deste material com uma solução complexante/tampo- 
nante de citrato-bicarbonato de sódio, seguido da adição de ditionito de sódio como agente redutor do $\mathrm{Fe}^{3+}$ a Fe ${ }^{2+}$ segundo metodologia descrita por Mehra \& Jackson (1960). Foram determinados os teores de $\mathrm{Fe}, \mathrm{Al}$ e $\mathrm{Mn}$ presentes no extrato por espectrofotometria de absorção atômica. Para o $\mathrm{Fe}^{2+}$ e o $\mathrm{Mn}^{2+}$ foi utilizado chama de ar-acetileno e para o $\mathrm{Al}^{3+}$ chama de óxido nitroso-acetileno. Os valores obtidos foram expressos na forma de $\mathrm{g} 100 \mathrm{~g}^{-1}$ de $\mathrm{Fe}_{\mathrm{d}}, \mathrm{Al}_{\mathrm{d}}$ e $\mathrm{Mn}_{\mathrm{d}}$ livres.

Foi realizada análise estatística dos micronutrientes zinco $(\mathrm{Zn})$, manganês $(\mathrm{Mn})$, cobre $(\mathrm{Cu})$ e ferro $(\mathrm{Fe})$ e dos óxidos de ferro. As variáveis foram submetidas aos testes de Levene (homogeneidade) e Shapiro-Wilk (normalidade), onde a variável ferro $(\mathrm{Fe})$ não atendeu aos testes de homogeneidade e normalidade, sendo os dados transformados em raiz quadrada de x. Após, foram feitas a análise de variância (teste F) e a comparação de médias (teste Scott-Knott) de todas variáveis, a uma probabilidade de 5\%. A análise estatística foi feita utilizando os softwares Sisvar (Ferreira 2003) e SAS (SAS Institute 1999). Foi realizada ainda uma Análise de Componentes Principais (ACP) para os micronutrientes e óxidos de ferro dos solos controles, solos adjacentes de $P c$ e $A g$ e coprólitos de $P c$ e $A g$, para ordenação das amostras em relação a estas variáveis (13 colunas, correspondentes ao número de variáveis $=$ micronutrientes e óxidos de ferro, e 120 linhas, correspondentes ao número de objetos = amostras), utilizando o software ADE-4 (Thioulouse et al. 1997).

\section{RESULTADOS}

De modo geral, o processo de produção dos coprólitos e a atividade das minhocas $P c$ e $A g$ no Latossolo Vermelho distroférrico (LVdf) em todos os sistemas de manejo (MT, PD, PDS e PT) teve efeito significativo $(\mathrm{p}<0,05)$ sobre os teores de micronutrientes disponíveis ( $\mathrm{Zn}, \mathrm{Cu}, \mathrm{Mn}, \mathrm{Fe}$ ) e sobre os teores dos óxidos de $\mathrm{Fe}$ amorfos e livres e Al e Mn presentes nos óxidos de ferro por substituição isomórfica (Tabela I).

Os teores de Zn disponível nos coprólitos foram maiores em todos os tratamentos (MT, PD, PDS e PT) para as duas espécies, sendo que os maiores aumentos ocorreram para a espécie $\mathrm{Ag}$. No solo em que as minhocas foram cultivadas (solo adjacente) foram observados aumentos somente para a espécie $P c$ (Tabela I). Para os teores de $\mathrm{Cu}$ disponível, não houve diferenças significativas $(\mathrm{p}>0,05)$ nos tratamentos entre o solo controle e os coprólitos, mas houve diminuições dos teores de $\mathrm{Cu}$ nos solos adjacentes (Tabela I).

Os teores de $\mathrm{Fe}$ disponível nos coprólitos não apresentaram diferenças significativas $(\mathrm{p}>0,05)$ quando comparados ao solo controle nos tratamentos MT, PD e PDS (Tabela I); porém, foi possível observar uma tendência na diminuição dos teores de Fe disponível nos coprólitos e nos solos em que as duas espécies foram cultivadas. Isto se confirma no tratamento PT onde as diferenças foram significativas. Para as duas espécies, o teor de Fe diminuiu nos coprólitos em comparação ao solo controle. 
Bartz et al.: Micronutrientes e óxidos de ferro em coprólitos de minhocas

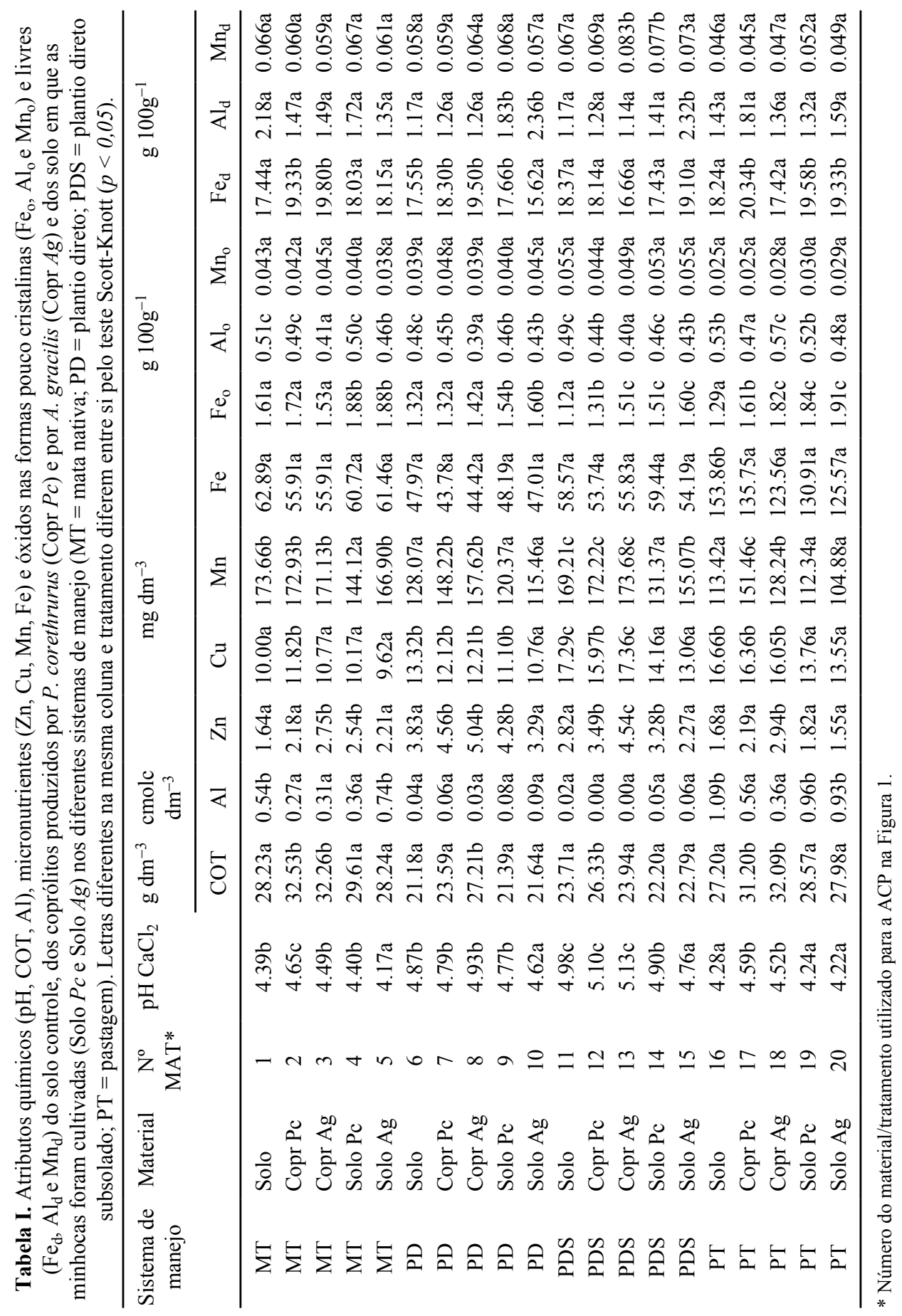


Com exceção do tratamento MT, houve concentração de Mn disponível nos coprólitos comparados ao solo controle e sua diminuição nos solos em que as minhocas foram cultivadas (Tabela I).

Em todos os tratamentos o solo em que as minhocas foram cultivadas teve aumentos nos teores de óxidos de ferro pouco cristalinos $\left(\mathrm{Fe}_{\mathrm{o}}\right)$, enquanto que para os coprólitos estas diferenças foram observadas nos tratamentos PDS e PT para ambas as espécies. Tanto para o solo em que as minhocas foram cultivadas como para os coprólitos, as maiores concentrações foram observadas para espécie $A g$ (Tabela I).

Houve variações significativas $(\mathrm{p}<0,05)$ nos teores de alumínio presentes como substituição isomórfica dos óxidos de ferro pouco cristalinos $\left(\mathrm{Al}_{\mathrm{o}}\right)$ (Tabela I). Em praticamente todos os tratamentos, os coprólitos comparados ao solo controle apresentaram os menores teores para as duas espécies de minhocas, com exceção dos coprólitos de $\mathrm{Ag}$ no tratamento PT, onde houve aumento dos teores de $\mathrm{Al}_{\mathrm{o}}$. Para o solo adjacente, houve diminuição significativa nos teores de $\mathrm{Al}_{\mathrm{o}}$ apenas para a espécie $A g$. Tanto para o solo em que as minhocas foram cultivadas como para os coprólitos, as maiores diminuições nos teores de $\mathrm{Al}_{\mathrm{o}}$ foram observadas para a espécie $\mathrm{Ag}$ (Tabela I). Enquanto aos teores de $\mathrm{Mn}_{\mathrm{o}}$, não houve variações significativas $(\mathrm{p}>0,05)$ entre os coprólitos e o solo controle (Tabela I).

Os teores de óxidos de ferro livre $\left(\mathrm{Fe}_{\mathrm{d}}\right)$ apresentaram diferenças nos valores entre os coprólitos, o solo controle e o solo adjacente. Os coprólitos produzidos pela espécie $P c$ apresentaram os teores mais elevados de $\mathrm{Fe}_{\mathrm{d}}$ comparados ao solo controle nos tratamentos MT e PT. A espécie $A g$ apresentou este comportamento somente no tratamento MT; nos tratamentos PDS e PT os teores de $\mathrm{Fe}_{\mathrm{d}}$ foram mais baixos (Tabela I). Para o solo em que as minhocas foram cultivadas houve diferença significativa nos valores de $\mathrm{Fe}_{\mathrm{d}}$ apenas no tratamento PT, onde foi observado aumento do teor de $\mathrm{Fe}_{\mathrm{d}}$ para as duas espécies, e no tratamento $\mathrm{PD}$, onde foi observado diminuição do teor de $\mathrm{Fe}_{\mathrm{d}}$ para a espécie $A g$.

Os teores de alumínio presentes como substituição isomórfica dos óxidos de ferro livres $\left(\mathrm{Al}_{\mathrm{d}}\right)$, apresentaram diferenças significativas $(\mathrm{p}<0,05)$ somente nos tratamentos PD e PDS, para o solo em que as duas espécies foram cultivadas, ocorrendo aumentos dos teores. Nos outros tratamentos não foi observada variação, tanto para os coprólitos como para o solo adjacente comparados ao solo controle (Tabela I).

Para os teores de $\mathrm{Mn}_{\mathrm{d}}$, não houve variações significativas entre os coprólitos, o solo adjacente e o solo controle, com exceção do tratamento PDS no qual foi observado um aumento significativo nos coprólitos de $A g$ e no solo adjacente (Tabela I).

$\mathrm{Na}$ matriz da ACP o primeiro (F1) e segundo (F2) eixos dos dados de micronutrientes e óxidos de ferro absorveram 38,26 \% e 13,84\% da inércia total $(52,1 \%)$, respectivamente (Fig. 1). Devido ao acentuado decaimento do gráfico de valores próprios, nenhum outro eixo foi retido para interpretação (Fig. 1a). O primeiro eixo (F1) está representado pelas variáveis $\mathrm{pH}, \mathrm{Zn}, \mathrm{Mn}, \mathrm{Mn}_{\mathrm{d}}$ e $\mathrm{Mn}_{\mathrm{o}}$ em oposição as variáveis 


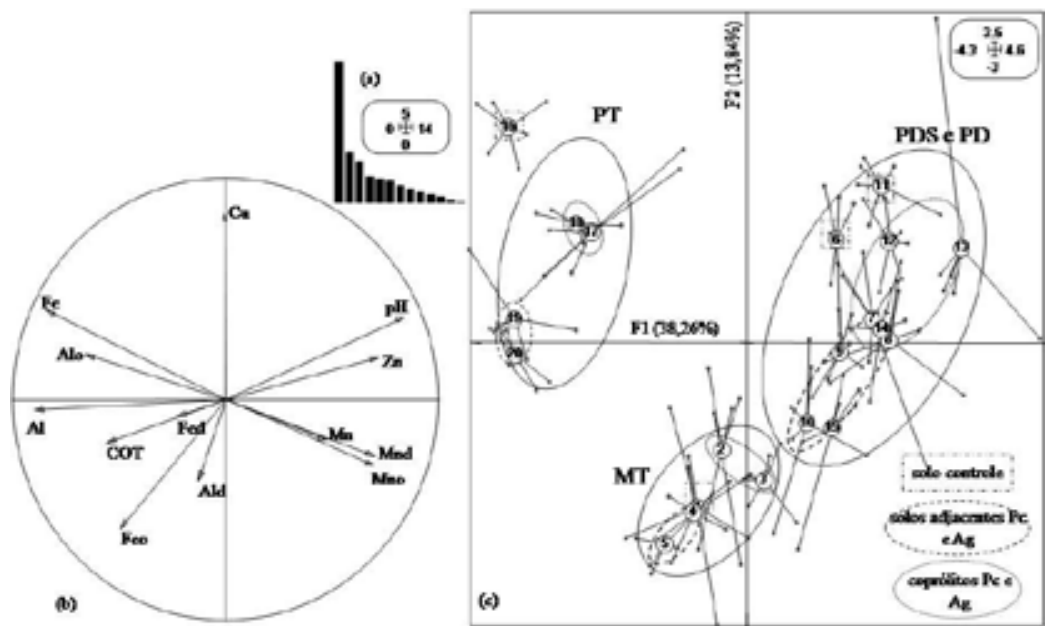

Figura 1. ACP dos micronutrientes e óxidos de ferro dos solos controle, solos adjacentes e coprólitos de $P c$ e $A g$. (a) diagrama de valores próprios; (b) círculo de correlações no plano F1-F2; (c) ordenação dos materiais no plano $\mathrm{F} 1, \mathrm{x}=38,3 \%$ e $\mathrm{F} 2, \mathrm{y}=13,8 \%$. Números: 1-5 = MT, 6-10 = PD, 11-15 = PDS e 16-20 = PT. Detalhes dos materiais (solo controle, copr $P c$, copr $A g$, solo $P c$ e solo $A g$ ) se encontram na coluna $\mathrm{N}^{o}$ MAT da Tabela $\mathrm{I}$. MT = mata nativa; $\mathrm{PD}=$ plantio direto; $\mathrm{PDS}=$ plantio direto subsolado; $\mathrm{PT}=$ pastagem.

$\mathrm{Fe}, \mathrm{Al}_{\mathrm{o}}, \mathrm{Al}, \mathrm{COT}$ e $\mathrm{Fe}_{\mathrm{d}}$. Este eixo separa os tratamentos provenientes das áreas de cultivo (PD e PDS) do tratamento PT, enquanto o tratamento MT se encontra intermediário às demais áreas (Fig. 1c). De modo que os tratamentos de plantio direto (PD e PDS) estão associadas a maiores teores de $\mathrm{pH}, \mathrm{Zn}, \mathrm{Mn}, \mathrm{Mn}_{\mathrm{d}}$ e $\mathrm{Mn}_{\mathrm{o}}$ e o tratamento PT a maiores teores de Fe, $\mathrm{Al}_{\mathrm{o}}, \mathrm{Al}, \mathrm{COT}$ e $\mathrm{Fe}_{\mathrm{d}}$ (Fig. 1b). O segundo eixo (F2) está representado pela variável $\mathrm{Cu}$ em oposição às variáveis $\mathrm{Fe}_{\mathrm{o}}$ e $\mathrm{Al}_{\mathrm{d}}$. Este eixo separa o tratamento MT das demais. Os materiais (solo, solo $P c$, solo $A g$, coprólito $P c$ e coprólito $A g$ ) de cada área foram ordenados significativamente a $\mathrm{p}<0,05$. Nos tratamentos PT e MT, os coprólitos produzidos por $P c$ e $A g$ se diferenciam das amostras de solos adjacentes que por sua vez, se diferenciam do solo controle. Nos tratamentos provenientes das áreas de cultivo (PD e PDS) as amostras se misturaram entres os tratamentos, mostrando grande similaridade entre as áreas; mesmo assim, ainda é possível observar um agrupamento dos coprólitos de $P c$ e $A g$ nos dois tratamentos que se diferenciam dos solos adjacentes de $P c$ e $A g$ e que por sua vez também se diferenciam dos solos controles.

\section{DISCUSSÃO}

Observou-se aumento no teor de $\mathrm{Zn}$ nos coprólitos de ambas $P c$ e/ou $A g$ em todos os tratamentos, e também um aumento no seu teor em solos cultivados com $P c$ em 
alguns tratamentos. Aumentos nos teores de Zn em coprólitos já foram observados por diversos autores (Ganeshamurthy et al. 1998, Bansal \& Kapoor 2000, Cheng \& Wong 2002) para várias espécies de minhocas (Drawida assamensis, Eisenia fetida e Pheretima sp., respectivamente). Para Cheng \& Wong (2002), o aumento do teor de Zn disponível nos coprólitos é resultado de interações entre as minhocas e os microorganismos associados à matéria orgânica.

A matéria orgânica, os óxidos de ferro e os minerais de argila influem na retenção do zinco no solo (Camargo 2006). Nascimento \& Fontes (2004) observaram que a matéria orgânica possui elevada afinidade pelo zinco e, no presente experimento, observou-se correlação positiva significativa entre o teor de $\mathrm{Zn}$ nos coprólitos e o conteúdo de COT dos mesmos no tratamento PD $\left(\mathrm{y}=0,1451 \mathrm{x}+0,9959, \mathrm{R}^{2}=0,6865, p<\right.$ 0,05). Portanto, o incremento observado nos teores de COT nos coprólitos de ambas as espécies (Tabela I) pode ter favorecido a adsorção do micronutriente, aumentando os teores disponíveis.

Foram observados poucos efeitos das minhocas sobre o teor disponível de $\mathrm{Cu}$ no solo, e na maioria dos casos o efeito foi negativo (especialmente em solos cultivados com minhocas). Estes resultados diferem daqueles de Ganeshamurthy et al. (1998), que encontraram aumentos significativos nos teores de $\mathrm{Cu}$ disponível nos coprólitos em comparação ao solo adjacente, e de Langenbach et al. (2002), que encontraram maiores valores de $\mathrm{Cu}$ nos solos incubados com Pc. Já Bansal \& Kapoor (2000), em um experimento para produção de vermicomposto com restos vegetais e esterco de gado utilizando a minhoca $E$. fetida, mostraram a diminuição dos teores de $\mathrm{Cu}$ na maioria dos tratamentos. O cobre aparece no solo na forma complexada e os complexos orgânicos formados são relativamente mais abundantes que os inorgânicos. A associação do $\mathrm{Cu}$ com o material orgânico é supostamente maior em solos ricos em matéria orgânica. A argila e a matéria orgânica são os componentes principais envolvidos na retenção do cobre no solo. Não é fácil discriminar o efeito de cada um, pois a matéria orgânica está intimamente ligada com a argila, formando um complexo argila-metal-matéria orgânica. $\mathrm{O}$ cobre é também adsorvido por óxidos de ferro, como acontece com o zinco. Um ponto a ser destacado aqui também é a dependência da adsorção ao pH do meio. Aumentando o pH, aumenta a adsorção de cobre pelos óxidos (Camargo 2006).

No presente estudo, observaram-se efeitos sobre o Fe disponível apenas em um sistema de manejo (PT), e o efeito das minhocas foi negativo (Tabela I). Em contraste, os teores de Fe foram até cinco vezes maiores na presença de minhocas $(P c)$ do que no solo sem elas (Langenbach et al. 2002). Ganeshamurthy et al. (1998) também apresentaram aumentos dos teores de Fe disponível, extraído em DTPA, até o sétimo dia de incubação, mas depois declínio até o final do período de incubação, que totalizou 28 dias. Neste mesmo trabalho, depois do sétimo dia de incubação, os teores de Fe disponível nos coprólitos foram menores do que os observados no solo adjacente. 
No presente estudo, os coprólitos foram coletados sempre após $>7$ dias, o que poderia estar influindo nos teores de Fe. A ligação de Fe com a matéria orgânica é muito importante, uma vez que possibilita sua movimentação através do solo, inclusive em direção à raiz, e evita sua precipitação no $\mathrm{pH}$ em que normalmente aconteceria (Camargo 2006). Entretanto, existem muito poucas evidências de que a complexação de Fe pela matéria orgânica do solo seja difundida (Goodman 1985). A interação do Fe com minerais de argila se dá ocupando lugares de troca ou, como no caso da caulinita, se adsorvendo na superfície do tetraedro de sílica (Camargo 2006).

Os teores de Mn disponível aumentaram nos coprólitos de ambas $P c$ e $A g$ (em dois tratamentos), confirmando tendências já observadas na literatura para outras espécies de minhocas (Ganeshamurthy et al. 1998). Já os valores de Mn nos solos cultivados com as minhocas foram menores que no solo controle (também em dois tratamentos), contrastando com resultados obtidos por Langenbach et al. (2002) para Pc. Schuman (1985) destaca que esse elemento está associado à matéria orgânica que é responsável pelo fornecimento de micronutrientes para as plantas. Os complexos orgânicos formados com o Mn são de pouca estabilidade, o que evidencia a pronta disponibilidade do elemento para o solo (Mcbride 1994). Outro fator que pode influenciar a disponibilidade do Mn é a alteração do $\mathrm{pH}$ do solo, pois seu aumento indisponibiliza o Mn para as plantas (Nascimento et al. 2005). No presente trabalho o efeito das minhocas sobre o $\mathrm{pH}$ foi significativo nos coprólitos (Bartz et al., este número) desta forma, o aumento de $\mathrm{pH}$ deveria afetar os teores de $\mathrm{Mn}$. Esse aumento, além do $\mathrm{pH}$ alcalino do sistema gastrointestinal das minhocas (Barois \& Lavelle 1986) e a forte complexação do alumínio pelos ácidos orgânicos produzidos, provavelmente foram os responsáveis pela redução no teor de Al observada tanto nos coprólitos de ambas $P c$ e $A g$, como no solo adjacente com $P c$ (tratamento MT e PT).

Considerando que os métodos de análise utilizados no presente estudo simulam a absorção desses nutrientes pela planta, o efeito observado demonstra que as minhocas favorecem a disponibilidade destes elementos para a planta, razão pela qual as raízes freqüentemente se concentram em coprólitos, buscando melhorar a nutrição da planta (Brown et al. 2004).

Os teores de ferro livre e amorfo determinados pelos dois métodos de dissolução seletiva no presente estudo, estão em conformidade com os valores observados para Latossolos desenvolvidos a partir do basalto no estado do Paraná (Costa et al. 1999). Em relação aos óxidos de ferro pouco cristalinos $\left(\mathrm{Fe}_{\mathrm{o}}\right)$ os altos valores observados são devido à grande quantidade de COT (Tabela I) do Latossolo amostrado nas diferentes condições de manejo (Kämpf \& Curi, 2000).

A elevada concentração de ferro livre em Latossolos derivados de basalto (Costa et al. 1999) e seu elevado grau de agregação não foram impedimentos para a absorção seletiva dos óxidos de ferro (hematita e maghemita) pelas minhocas, especialmente da espécie $P c$ nos tratamentos MT e PT. Alterações na distribuição relativa destes 
óxidos de ferro e a possível formação de goethita a partir do $\mathrm{Fe}_{\mathrm{o}}$, no trato intestinal das minhocas, serão objetivo de futuras pesquisas.

Oyedele et al. (2006) observaram que os coprólitos das minhocas possuem teores mais elevados de óxidos de ferro e alumínio pouco cristalinos, quando comparados ao horizonte A e B do solo utilizado, e que, em relação aos óxidos de ferro e alumínio livres, os teores mais elevados foram encontrados no horizonte B. Oyedele et al. (2006) atribuem a conversão das frações livres às formas amorfas mais ativas ao processo de moagem e mistura na moela das partículas de solo ingeridas pela minhoca. Na Tabela I observa-se que os aumentos nos teores de óxidos de ferro amorfos e livres também devem ser atribuídos à transformação do Fe disponível (Mehlich1) em óxidos de ferro amorfos e livres, pois é clara a redução dos teores de Fe disponível nos coprólitos das minhocas e no solo em que as minhocas foram cultivadas (Tabela I).

São conhecidas as relações existentes entre a quantidade de matéria orgânica, óxidos de ferro, alumínio e manganês, $\mathrm{pH}$ e a disponibilidade de micronutrientes (Schuman 1985, Araújo 2000, Sauvé et al. 2000, Nascimento \& Fontes 2004, Mellis et al. 2004, Azevedo \& Bonumá 2004, Nascimento et al. 2005). Este trabalho mostra que a adição da matéria orgânica e os aumentos nos teores de óxidos de ferro amorfos e livres promovidos pelas atividades das minhocas e/ou organismos associados a elas podem ter um efeito direto sobre a disponibilidade dos micronutrientes no solo. Contudo, estudos futuros devem investigar esses efeitos mais a fundo, para determinar os mecanismos pelos quais as minhocas afetam os minerais da argila (e o intemperismo), e assim, a disponibilidade de nutrientes para as plantas. Além disso, o presente estudo contemplou apenas duas das mais conhecidas e comuns espécies encontradas em zonas agrícolas do Brasil e da América Latina; existem ainda várias outras espécies comuns nos solos agrícolas (e.g., Dichogaster spp.), que deverão ainda, ser alvo de futuras pesquisas sobre os efeitos nos processos de intemperismo e na fertilidade do solo.

\section{AGRADECIMENTOS}

Este estudo teve apoio do CNPq (bolsa para G. Brown), da Fundação para Agricultura Sustentável (Agrisus) e do Conselho de Apoio à Pesquisa e Ensino Superior (Capes), através da concessão de bolsas de estudos a M. L. C. Bartz e apoio financeiro ao projeto.

Agradecemos ao Sr. Arnoldo Bulle, proprietário da Fazenda Bulle, ao Sr. João Aparecido Milani, proprietário da Estância Santo Ângelo, ao Sr. Genoefa Totti Venturelli, proprietário, e ao Sr. Oscar Recio Loureto, administrador da Fazenda Escalada e ao Sr. Herbert Arnold Bartz, proprietário da Fazenda Rhenânia, por concederem suas áreas para coleta de solo e realização deste estudo. 
Bartz et al.: Micronutrientes e óxidos de ferro em coprólitos de minhocas

\section{LITERATURA CITADA}

Araújo, W. S. 2003. Influência das propriedades físicas e químicas de solos intemperizados na absorção de chumbo, cobre e zinco. Revista Floresta e Ambiente. 7(1): 167-180.

Azevedo, A. C. \& A. G. Bonumá. 2004. Partículas coloidais, dispersão e agregação em Latossolos. Ciência Rural. 34(2): 609-617.

Bansal, S. \& K. K. Kapoor. 2000. Vermicomposting of crop residues and cattle dung with Eisenia foetida. Bioresource Technology. 73: 95-98.

Barker, W. W., S. A. Welch, S. Chu \& J. F.Banfield. 1998. Experimental observations of the effects of bacteria on aluminosilicate weathering. American Mineralogist. 83: 1551-1563.

Barois, I., G. Villemin, P. Lavelle \& F. Toutain. 1993. Transformation of the soil structure through Pontoscolex corethrurus (Oligochaeta) intestinal tract. Geoderma. 56: 57-66.

Barois, I., P. Lavelle, M. Brossard, J. Tondoh, M. Martinez, J. Rossi, B. Senapati, A. Angeles, C. Fragoso, J. Jiménez, T. Decaëns, C. Lattaud, J. Kanonyo, E. Blanchart, L. Chapuis, G. G. Brown \& A. G. Moreno. 1999. Ecology of earthworm species with large environmental tolerance and or extended distributions. Pp.57-85. In: P. Lavelle, L. Brussaard and P. F. Hendrix (eds.). Earthworm management in tropical agroecosystems. CABI International, Wallingford.

Basker, A., J. H. Kirkman \& A. N. Macgregor. 1992. The availability of potassium in soil: an incubation experiment. Biology and Fertility of Soils. 14: 300-303.

Basker, A., A. N. Macgregor \& J. H. Kirkman. 1993. Exchangeable potassium and other cations in non-ingested soil and casts of two species of pasture earthworms. Soil Biology and Biochemistry. 25: 1673-1677.

Basker, A., J. H. Kirkman \& A. N. Macgregor. 1994. Changes in potassium availability and other soil properties due soil ingestion by earthworm. Biology and Fertility of Soils. 17: 154-158.

Brown, G. G., C. A. Edwards \& L. Brussaard. 2004. How earthworms affect plant growth: burrowing into the mechanisms. Pp. 13-49. In: C. A. Edwards (Ed.). Earthworm ecology. CRC Press, Boca Raton.

Camargo, O. A., A. C. Moniz, J. A. Jorge \& J. M. A. S. Valadares. 1986. Métodos de análise química, mineralogia e física de solos do Instituto Agronômico de Campinas. Boletim Técnico ${ }^{\circ}{ }^{106}$, IAC, Campinas.

Camargo, O. A. 1991. Reações e interações de micronutrientes no solo. Pp. 243-272. In: M. E. Ferreira and M. C. P. Cruz (Eds.). Micronutrientes na agricultura. POTAFOS/CNPq, Piracicaba.

Camargo, A. O. 2006 Reações e interações de micronutrientes no solo. Artigo em Hipertexto disponível em: $<$ http://www.infobibos.com/Artigos/2006_3/Micronutrientes/Index.htm>.

Cheng, J. \& H. M. Wong. 2002. Effects of earthworms on Zn fractionation in soils. Biology \& Fertility of Soils. 36: 72-78.

Chen, J., H. P. Blume \& L. Beyer. 2000. Weathering of rocks induced by lichen colonization - a review. Catena. 39: 121-146.

Cortez, J. \& M. B. Bouché. 1998. Field decomposition of leaf litters: earthworm-microorganism interactions - the ploughing-in effect. Soil Biology and Biochemestry. 30(6): 795-804.

Costa, A. C. S., J. M. Bigham, F. E. Rhoton \& S. J. Traina. 1999. Quantification and characterization of maghemite in Soils derived from volcanic rocks in southern Brazil. Clays and Clay Minerals. 47(4): 466-473.

De Vleeschauwer, D. \& R. Lal. 1981. Properties of worm casts under secondary tropical forest regrowth. Soil Science. 132: 175-181.

Dias, N. M. P., L. R. F. Alleoni, J. C. Casagrande \& O. A. Camargo. 2003. Energia livre da reação de adsorção de cádmio em Latossolos ácricos. Ciência Rural. 33(5): 829-834. 
Edwards, C. A. \& P. J. Bohlen. 1996. Biology and ecology of earthworms, $3^{\text {rd }}$ Ed. Chapman \& Hall, London.

Embrapa. 1999. Manual de análises químicas de solos, plantas e fertilizantes. Embrapa, Brasília.

Evans, A. C. 1948. Studies on the relationships between earthworms and soil fertility: II. Some effects of earthworms on soil structure. Annals of Applied Biology. 35: 1-13.

Ferreira, D. F. 2003. Programa de análises estatísticas (Statistical Analysis Software) e planejamento de experimentos. Universidade Federal de Lavras, Lavras.

Ganeshrmurthy, K., K. M. Manjaiah \& A. Subba Rao. 1998. Mobilization of nutrients in tropical soils through worm casting: availability of macronutrients. Soil Biology and Biochemistry. 30(13): 1671-1676.

Goodman, B. A. 1985. The characterization of iron complexes with soil organic matter. Pp. 842-51 In: J. W. Stucki, A. Goodman and U. Schwertmann (Eds.). Iron in soils and clay minerals. NATO Advanced Study Institute, Bad Windsheim.

Hinsinger, P., O. N. F. Barros, M. F. Benedetti, Y. Noack \& G. Callot. 2001. Plant-induced weathering of a basaltic rock: experimental evidence. Geochimica et Cosmochimica Acta. 65: 137-152.

Hullegale, N. R \& H. C. Ezumah. 1991. Effects of cassava-based cropping systems on physical-chemical properties of soil and earthworm casts in a tropical Alfisol. Agriculture, Ecosystems \& Environment. 35: 55-63.

Joshi, N. V. \& B. V. Kelkar. 1952. The role of earthworms in soil fertility. International Journal of Agricultural Science. 22: 189-196.

Kämpf, N. 1988. Ferro no solo. Pp. 35-71. In: Reunião sobre Ferro em Solos Inundados, 1, Anais. Goiânia.

Kämpf, N. \& N. Curi. 2000. Óxidos de ferro: indicadores de ambientes pedogênicos. Pp. 107-138 In: R. F. Novais, V. H. Alvarez and C. E. G. R. Schaefer (Eds.). Tópicos em Ciência do Solo VI. Sociedade Brasileira de Ciência do Solo, Viçosa.

Kizilkaya, R. 2004. $\mathrm{Cu}$ and $\mathrm{Zn}$ accumulation in earthworm Lumbricus terrestris L. in sewage sludge amended soil and fractions of $\mathrm{Cu}$ and $\mathrm{Zn}$ in casts and surrounding soil. Ecological Engineering. 22: 141-151.

Lal, R. \& D. De Vleeschauwer. 1982. Influence of tillage methods and fertilizer application on chemical properties of worm castings in a tropical soil. Soil Tillage Research. 2: 37-52.

Lal, R. \& O. O. Akinremi. 1983. Physical properties of earthworm casts and surface soil as influenced by management. Soil Science. 135: 114-122.

Langenbach, T., M. V. de S. Inacio, A. M. de Aquino \& B. Brunninger. 2002. Effects of earthworm Pontoscolex corethrurus on distribution of acaricida dicofol in a Podzolic soil. Pesquisa Agropecuária Brasileira. 37(11): 1663-1668.

Lee, K. E. 1983. Soil animals and pedological processes. Pp. 629-644. In: Soils: an Australian viewpoint. CSIRO Division of Soils. Academic Press, London.

Lee, K. E. 1985. Earthworms: their ecology and relations with soil and land use. Academic Press, London.

McBride, M. B. 1994. Environmental chemistry of soils. Oxford University Press, New York.

Mehra, O. P. \& M. L. Jackson. 1960. Iron oxide removal from soil and clays by a dithionite-citrate system buffered with sodium bicarbonate. Clays and Clay Minerals. 7: 317-327.

Mellis, E. V., M. C. P. Cruz \& J. C. Casagrande. 2004. Nickel absorption by soils in relation to pH, organic matter and iron oxides. Scientia Agricola. 61(2): 190-195.

Morgan, J. E. \& A. J. Morgan. 1998. The distribution and intracellular compartmentation of metals in the endogeic earthworm Aporrectodea caliginosa sampled from an unpolluted and metal-contaminated site. Environmental Pollution. 99: 167-175. 
Nascimento,C.W.A.\& R. L.F. Fontes. 2004. Correlação entre características de Latossolos e parâmetros de equações de adsorção de cobre e zinco. Revista Brasileira de Ciência do Solo. 28: 965-971.

Nascimento, C. W. A., P. V. V. Leite, R. S. M. P. Nascimento \& E. E. C. Melo. 2005. Influência da calagem no fracionamento e na disponibilidade de manganês em solos de Pernambuco. Agropecuária Técnica. 26(1): 22-28.

Needham, S. J., R. H. Worden \& D. McIlroy. 2004. Animal-sediment interactions: the effect of ingestion and excretion by worms on mineralogy. Biogeosciences Discussions. 1: 533-559.

Nooren, C. A. M., N. van Breemen, J. J. Stoorvogel \& A. G. Jongmans. 1995. The role of earthworms in the formation of sandy surface soils in a tropical forest in Ivory Coast. Geoderma. 65: 135-148.

Oyedele, D. J., P. Schjønning \& A. A. Amusan. 2006. Physicochemical properties of earthworm casts and uningested parent soil from selected sites in southwestern Nigeria. Ecological Engineering. 28: 106-113.

Quadros, R. M. B., A. F. J. Bellote \& J. A. Dionísio. 2002. Observações sobre propriedades químicas do solo e de excrementos de minhocas em plantios de Eucaliptus grandis. Boletim de Pesquisa Florestal. 45: 29-39.

Santelli, C. M., S. A. Welch, H. R. Westrich \& J. F. Banfield. 2001. The effect of Fe-oxidizing bacteria on Fe-silicate mineral dissolution. Chemical Geology. 180: 99-115.

SAS. 1999. Procedure guide for personal computers, 5th Ed. SAS Institute, Cary.

Sauvé, S., W. Hendershot \& H. E. Allen. 2000. Solid-solution partitioning of metals in contaminated soils: dependence on $\mathrm{pH}$, total metal burden and organic matter. Environmental Science and Technology. 34: 1125-1131.

Shipitalo, M. J. \& R. Protz. 1989. Chemistry and micromorphology of aggregation in earthworm casts. Geoderma. 45: 357-374.

Schuman, L. M. 1985. Effect of organic matter on the distribution of manganese, copper, iron and zinc in soil fractions. Soil Science. 146: 192-198.

Song, W., N. Ogawa, C. T. Oguchi, Y. Hatta \& Y. Matsukara. 2006. Effect of Bacillus subtilis on granite weathering: A laboratory experiment. Catena. 70: 275-281.

Suzuki, Y., T. Matsubara \& M. Hoshino. 2003. Breakdown of mineral grains by earthworms and beetle larvae. Geoderma. 112: 131-142.

Thioulouse, J., D. Chessel, S. Dolédec \& J. M. Olivier. 1997. ADE-4: a multivariate analysis and graphical display software. Statistic Computer. 7: 5-83. 